\section{INTERDENTAL GELS AND BRUSHES}

Among the exhibitors at BDTA Dental Showcase will be Danish company Tandex on stand U10, renowned for its high quality dental products, including interdental gels and brushes.

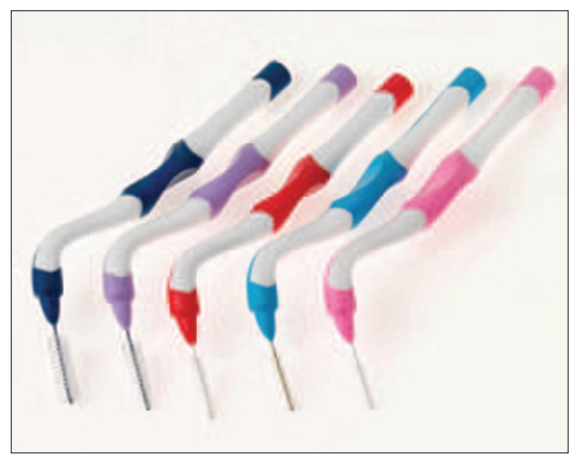

This year delegates will be treated to a well equipped stand featuring the full range of Tandex products and including the new Flexi Max interdental brush, which was launched in May.

The Flexi Max shares many of the outstanding features of Tandex's popular Flexi range such as colour coded, soft grip handles, but has an angled head and long handle to make cleaning easier and more efficient for patients with manual dexterity problems.

This year Tandex celebrates 80 years in the dental business and will be proving to delegates at the BDTA that it truly deserves its reputation for excellence. Reader response number 58

\title{
JOIN THE ANNIVERSARY CELEBRATIONS WITH GAMES AND PRIZES
}

DPAS is inviting visitors to this year's BDTA Dental Showcase to join them on stand B22 for cake, games and prizes in celebration of the company's 15th anniversary.

Since 1996 DPAS has been a leading provider of cost effective administration services for dentists who want to enjoy the benefits of a dental plan while maintaining and promoting the integrity of their own practice brand. DPAS have the experience and expertise to help you create and establish a plan specifically designed around your patients' needs, using your own practice branding to help further establish your market position and ultimately increase the value of your practice.

Whether considering conversion from the NHS or working within an established private or mixed practice, DPAS have everything you need to support the introduction and ongoing promotion of your plan, without the costly extras often associated with other providers. For the past 15 years, DPAS have been fully committed to outstanding customer service levels and have a real dedication to understanding and meeting dental team's needs, making them a natural choice for all practitioners endeavouring to find innovative ways to attract and retain patients, while also securing their finances.

To find out how a DPAS practice branded dental plan can work in your practice, join them on stand B22. Reader response number 59

\section{DEDICATED TO DENTAL FURNITURE}

Now a full member of the BDTA, with a 20-year track record of serving the medical and healthcare sectors, Suffolk-based Plinth 2000 has established a business area dedicated to the dental equipment market, under the name Plinth Dental. It has secured an exclusive distribution deal with one of the world's leading dental furniture and equipment manufacturers, Gnatus, to market and supply its dental sets, X-ray equipment and accessories in the UK, Ireland, Belgium and the Netherlands. Chairs such as the Syncrus HLX are being specified for the European market, complete with Trendelenburg tilt and a choice of dental delivery units, and Plinth Dental is recruiting a network of engineers to deliver service and support to the dental profession. Visit Plinth Dental on stand P19. Reader response number 60

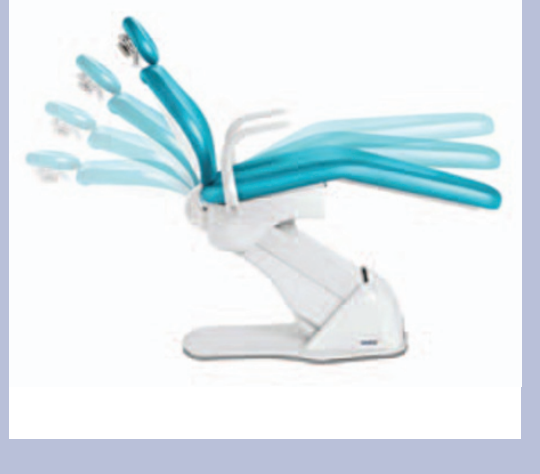

